\title{
El reconocimiento de los niños y niñas como "personajes» políticos a través de las narrativas ${ }^{1}$
}

Recognizing Children as Political “Characters” Through Narratives

\section{Cristian Giraldo Castaño*}

(iD) https://orcid.org/0000-0002-4967-1820

\section{Lina Marcela Castañeda Macias ${ }^{* *}$}

(iD) https://orcid.org/0000-0001-8615-8949

Tipo de Artículo: Informes de Investigación y ensayos inéditos

Doi: 10.17533/udea.unipluri.20.2.09

Giraldo Castaño, C., y Castañeda Macias, L. M. (2020). El reconocimiento de los niños y niñas como «personajes» políticos a través de las narrativas. Uni-Pluriversidad, 20(2). e2020209. doi: 10.17533/udea.unipluri.20.2.09

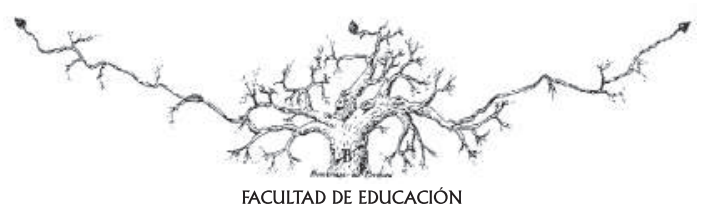

Recibido: 2020-05-04 • Aprobado: 2020-10-28

* Licenciado en Pedagogía Infantil. Universidad de Antioquia, Colombia. Email: cristian.giraldoc@udea.edu.co

** Licenciada en Pedagogía Infantil. Universidad de Antioquia, Colombia. Email: castam25@hotmail.com 


\title{
Resumen
}

El presente artículo es una síntesis de un proyecto de investigación enmarcado en la formación ciudadana. Su objetivo es analizar las posibilidades para la configuración de la subjetividad política desde las narrativas de niños y niñas de 9 y 12 años, de una institución educativa pública de Medellín. La investigación se desarrolla desde un enfoque cualitativo, con un diseño biográfico-narrativo para dotar de sentido las experiencias vividas y contadas por los niños y niñas. El análisis se presenta a la luz del entramado de sentidos que despliegan las narrativas en relación con la subjetividad política. Se concluye que la posibilidad que brindan las narrativas para la configuración de dicha subjetividad es el reconocimiento de «Yo alteridad: sí mismo como otro» de los niños y las niñas.

Palabras clave: subjetividad política, narrativas, reconocimiento, formación ciudadana.

\begin{abstract}
This article is a synthesis of a research project delimited by citizen training. The objective is to analyze possibilities to configure a political subjectivity from the narratives by boys and girls aged 9 and 12, from a public educational institution in Medellín. The research is developed according to a qualitative approach, with a biographical-narrative design to provide meaning to the experiences that children lived and told. Analysis is presented considering the network of meanings that narratives unfold in relation to the political subjectivity. As conclusion. The report concludes that the possibility offered by the narratives to configure the subjectivity is the recognition of boys and girls as "I alterity: myself as another".
\end{abstract}

Keywords: political subjectivity, narratives, recognition, citizenship education. 


\section{INTRODUCCIÓN}

En las últimas décadas, impulsados por la Convención de los Derechos del Niño (1989), se ha avanzado en condiciones materiales, institucionales, legales, culturales y sociales que permitan el reconocimiento y el efectivo goce de los niños y niñas como sujetos de derechos y sujetos políticos. Con ello, se han configurado nuevas prácticas de crianza y procesos educativos para posibilitar su formación como ciudadanos, intentando superar concepciones de infancia en las que se les representa como maleables, el ciudadano del mañana, sin capacidad de agencia.

Ante las nuevas maneras de pensar la infancia y la emergencia de otras formas de ser niño, se hace necesario crear espacios de formación ciudadana en los que los niños y niñas sean protagonistas en la construcción de sus biografías -individuales y colectivas- desde sus experiencias y emociones, desde lo lúdico y lo estético; no solo desde la racionalidad, discursos, saberes y el poder del mundo adulto. De esta manera, se plantea un gran reto ético, político y pedagógico para construir ambientes y propuestas educativas en la que no solo los adultos reconozcan a los niños y niñas como sujetos políticos, sino que, además, ellos mismos puedan reconocerse como tal, para que las generaciones adultas no sigan siendo la voz de las nuevas generaciones ni que la capacidad de agencia y participación de estas quede tutelada por las primeras.

Como afirma Kohan (2007), la subjetivación política no trata solo de derechos, sino, sobre todo, de experiencia; se trata de posibilitarle a los sujetos la oportunidad de afirmar, significar y dotar de sentidos sus subjetividades políticas, lo cual debe empezar por un trabajo sobre sí mismo, sobre la propia biografía. La condición como sujetos políticos debe partir de la capacidad de construir y formar -en términos de Delory (2015)- nuestra condición biográfica; es decir, desde la capacidad de narrarnos a nosotros mismos y al mundo que habitamos. Por lo tanto, la formación ciudadana de niños y niñas, desde sus subjetividades, estaría atravesada por sus voces y narrativas de sus propias experiencias. En este sentido, en el presente artículo se indaga por las posibilidades de configurar la subjetividad política desde las narrativas de 15 niños y niñas de 9 a 12 años en una institución educativa pública de Medellín.

\section{Travesía MetodológicA}

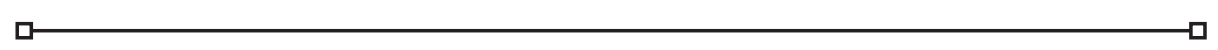

El proyecto de investigación se desarrolló a partir de un enfoque cualitativo, el cual es entendido como "un modo de encarar el mundo desde la interioridad de los sujetos sociales y de las relaciones que establecen con los contextos y con otros actores socia- les" (Galeano, 2004, p. 16). Es decir, desde este enfoque se pretendió familiarizarse con realidades socio-culturales de los niños y niñas para comprender tanto sus dimensiones personales -motivaciones, creencias, pensamientos, intereses, necesidades, sueños, 
experiencias y demás situaciones que guían sus acciones-, como las dinámicas interactivas que contribuyen a la configuración de sentidos y significados que le atribuyen al mundo que los rodea.

La investigación tuvo un diseño biográfico-narrativo por medio del cual se estudió la experiencia y la transformación de los sujetos. Es decir, la experiencia se estructuró y organizó narrativamente para comprender-se, para entender la propia historicidad de los niños y niñas de manera sensible, reflexiva, crítica y consciente. Desde esta perspectiva, "la experiencia se convirtió en el bastión de conocimiento que nutrió la investigación" (Piedrahíta, 2015, p. 74).

Las técnicas que posibilitaron recopilar y construir los datos en el proyecto fueron de carácter dialógico, es decir, intersubjetivo, como una posibilidad para comprender creencias, pensamientos, modos de vida y realidades de los niños y niñas. Las técnicas fueron: revisión documental; grupo focal, conformado por la población participante (15 niños y niñas entre los 9 y 12 años); taller investigativo y observación participante.

Finalmente, para alcanzar el objetivo de analizar la configuración política de los niños y las niñas que puede emerger de sus narrativas, se rastrearon los elementos constitutivos de este tipo de subjetividad. Para ello, se realizó una matriz donde todas las narrativas que fueron registradas en el proceso de investigación se separaron por 'trozos narrativos', atendiendo a los elementos de la subjetividad política que cada uno de ellos contenía - por 'trozos narrativos' nos referimos a la división de la información recogida en pequeños micro-relatos-, para analizar la información de forma posterior por medio de la hermenéutica como una herramienta fundamental para la comprensión e interpretación de la realidad. Lo que está en juego en la hermenéutica, de acuerdo con Ricoeur (2006), es la recuperación del sentido de los 'textos', una comprensión del ser mediante el lenguaje; en últimas, es el arte de comprender las manifestaciones textuales de la vida, de la experiencia vivida — sea cual fuere_-, es la captura del ser por el lenguaje.

\section{Resultados: Sintagma de la subjetividad política}

La subjetividad política, de acuerdo con los referentes teóricos que guiaron esta investigación, está constituida por diferentes elementos (Ruíz y Prada, 2012) y tramas (Alvarado, 2009). Cuando estas tramas y elementos se entraman integran lo que hemos llamado 'sintagma de la subjetividad política'. Para el análisis de la información, se estudiarán cada una de estas subcategorías de manera diferenciada y por segmentos, no porque haya disyunción entre ellos, sino para poder dar cuenta de cada uno.

\section{Subjetividad política como identidad}

La subjetividad política es una construcción de la identidad que se va configurando hermenéuticamente de las narraciones -la propia y la de otros-. De estas narraciones vamos construyendo nuestro «personaje» ${ }^{2}$, cuya identidad es una construcción propia o impuesta, o ambas; siendo así, un campo de tensión entre los discursos y las implicaciones semántica de las formas de nombrar[nos] y reconocer[nos]. En la configuración de la identidad de estos niños y niñas, en 
cuanto a sujetos públicos, se producen conflictos identitarios que son construidos por instituciones que intervienen en estas poblaciones. Así, son construidos como unos ‘otros' que están «en los bordes de la polis», como si no pertenecieran a la ciudad, física y simbólicamente, y así lo manifiestan: "los fines de semana voy a Medellín con mi tío", como si ellos no hicieran también parte de esta ciudad. Esto es un estigma territorial en el que se perciben por fuera de la ciudad y, por lo menos simbólicamente, se aíslan políticamente de ella cuando no se sienten adheridos y no encuentran un anclaje al mundo político ni un vínculo institucional.

Además, la identidad de los niños y niñas se va construyendo cuando son representados como 'beneficiarios'. De esta manera, como afirma Ricoeur (1996), "enfrentado a la beneficencia [...] el otro parece reducido sólo a la condición de recibir" (p.198). Efectivamente, estos niños y niñas no sólo son, sino que también se identifican y posicionan como 'beneficiarios' pues reciben un subsidio por parte del Estado. Este reconocimiento como 'beneficiarios', como aquellos que deben ser asistidos, causaba que, al inicio de la investigación, cuando se les proponía que imaginaran la manera de resolver sus problemas, siempre recurrieran y dependieran de un subsidio estatal para solucionarlos. Esto impedía que imaginaran otras alternativas restringiendo, por lo menos simbólicamente, su capacidad de agencia.

Además de las condiciones materiales, como la pobreza, también hay acciones simbólicas, como la etiqueta de 'beneficiarios', que contribuyen o no a su subjetivación, perpetuando sus condiciones de marginalidad, reforzando las exclusiones y generando una identidad etiquetada con calificativos que los minoriza. Estas etiquetas, siendo 'actos del lenguaje', van construyendo sus 'personajes', en este caso, la construcción como 'sujetos políticos'. Debido a que el lenguaje tiene un carácter performativo, se está contribuyendo a legitimar, reproducir, fijar y reafirmar su papel social en calidad de 'beneficiarios'.

Narrar y crear su personaje como 'beneficiarios' va marcando cómo se perciben a sí mismos, cómo se perciben en relación con su rol social, por tanto, se determina su capacidad de acción. Este personaje crea dependencia a los programas gubernamentales en los que reciben un subsidio. Las narraciones operan como un 'libreto' en el que ellos internalizan actitudes y creencias carenciales en cuanto a agentes sociales. ¿Qué 'personaje' se forma bajo estas concepciones: beneficiarios o ciudadanos?

\section{Subjetividad política como reconocimiento de sí mismos}

Inicialmente, en los significados sobre lo 'político' de los niños y niñas primaban las representaciones asociadas a cargos administrativos con concepciones negativas de lo que es un político. Muestra de ello es cuando expresaban "un político es el que mata", "los que tienen plata", "trituran a los humanos". Igualmente, las imágenes que tenían los niños y niñas de sí mismos, en cuanto a su condición etaria -como una predisposición a no poder ser agentes políticos por dicha condición- y su posicionamiento de beneficiarios — sin capacidad de agencia-, se fue transformando cuando se ampliaron las nociones de lo que es ser-sujeto-político. Algunos niños y niñas reconocieron que incluso con la edad que tienen pueden ser sujetos 
políticos y realizar acciones políticas como las que hizo Héctor Abad Gómez, quien fue un referente biográfico-narrativo que se les mostró en el desarrollo de la investigación.

En las primeras sesiones del trabajo de campo, los niños y niñas no reconocían que pudieran realizar acciones de carácter político, sin embargo, en el transcurso de la investigación emergían procesos de identificación como sujetos políticos cuando decían: "yo soy, todos podemos ser [sujetos políticos]", "Yo mismo puedo hacer acciones políticas como las de Héctor Abad". Ese "yo soy', ‘todos podemos' y 'yo mismo', más que una construcción gramatical, devela que en estos niños y niñas se formaron imágenes en las que se identificaban como sujetos con capacidad de agencia; por lo menos narrativamente, creen que pueden hacerlo y otorgan ciertas capacidades a su 'personaje' dentro de unas narrativas sociales. De acuerdo con Vargas (2007), la subjetivación política es una nueva inscripción en el lenguaje, es un proceso 'literario' de alteración de las palabras y de los enunciados en donde el sujeto se representa y reconoce como capaz de ciertas realizaciones por medio de la imaginación narrativa.

Con estas nuevas identificaciones se provocó una ruptura representacional, un quiebre en la manera de pensar el mundo político, por lo que sus experiencias vividas ahora acogen un nuevo sentido, las nuevas representaciones sobre lo que es lo político integran nuevas imágenes que amplían sus comprensiones. Esto permitió una revaloración de las acciones cotidianas.

Los procesos identitarios, como con Héctor Abad, permitieron que eso de 'sujeto político' se hiciera concreto en este persona- je al cual se le identificó como un ser-político. De ese modo, identificaron en Héctor Abad una personificación o materialización de lo político; él es una subjetividad política encorpada, es decir, es embodied: lo político encarnado en un cuerpo. En esa manera concreta de lo que es ser un sujeto político se puede resaltar que, en la configuración de la subjetividad política, hacer inteligible lo político en personajes reales y concretos permite procesos identitarios. Esta identificación posibilitó que los participantes se reconocieran y se sintieran llamados a actuar en función de eso que valoran. Estas narraciones se convierten en un 'territorio simbólico-conceptual' en donde ellos y ellas se vinculan a valores y formas de vida.

\section{Subjetividad política es ser memoria, dotar de sentidos políticos a los recuerdos}

La comprensión de lo narrado es una comprensión de sí mismo, un acto de reflexividad que se logra por la capacidad de recordar, de hacer conciencia de sí. Hacer una relectura de algunos hechos del pasado permitió a los niños y niñas recordar hechos en los que han sido agentes políticos. Estos ejercicios de memoria permiten que en la recuperación de la experiencia vivida haya creación de sentidos políticos en los que se da una construcción de 'sí mismo como otro'; esto es, pudieron reconocer que sus acciones narradas son de apertura a los 'otros', cuando hay un encuentro de alteridades, yo-tú, pues sus autobiografías no son ensimismamiento, por el contrario, son acciones para el 'otro'. Los recuerdos fueron reinterpretados en actividades narrativas enmarcadas en preguntas por lo político, narraron vivencias en las que eran sujetos violentos, pero también vivencias en las que han sido sujetos 
de paz. De esta manera, "compartir esas memorias, hacerlas públicas involucra la capacidad de narrarlas y la narración no sólo exige recorte, delimitación, sino también [...] significación personal de lo vivido y de lo recordado" (Ruíz y Prada, 2012, p.64). En los recuerdos y narraciones reconocían las acciones pasadas que han sido políticas, por ejemplo, "yo soy político porque les llevo cosas a unas personas que viven por allá, yo les ayudo"; de esta manera catalogaban estas acciones con sentidos políticos. Así, lo importante de un acontecimiento no es que acontezca, sino que se le pueda atribuir sentidos, pues, para ser calificado como acción política es necesario que además de realizada se "[...] establezca una relación significativa, interpretativa, hermenéutica" (Weber, citado en Mèlich, 1994, p.85), más allá del acto mismo, lo que lo hace político es el sentido que el propio sujeto [re] construye. Es así como los niños y niñas se configuran como 'personajes' políticos al ir tomando conciencia sobre las 'actuaciones' que implica ser sujeto político, tal como lo expresan: "Yo fui político ayudándole a una señora a subir unos adobes", "Yo soy un sujeto político porque ayudo a los viejitos de la calle y botando la basura".

También, al inicio de la investigación, cuando a los niños y niñas se les preguntaba, por ejemplo, quiénes hacen la paz, entre sus respuestas encontrábamos cosas tales como: "Nadie", "el Papa" o "el presidente"; pero para las sesiones finales los niños y las niñas se reconocían como agentes de paz, incluso se apropiaban lingüísticamente de ella. Ello se evidencia en sus narrativas cuando, al narrar actos de paz, ellos decían "mi paz". Este pronombre posesivo indica una acogida, hace suya la paz mediante el lenguaje. Con esto, ellos y ellas tienen un relato pro- pio sobre acciones de paz, se designan a sí mismos como hacedores de paz y, mediante las narrativas, van edificando una memoria política.

\section{Subjetividad política como conciencia histórica}

La conciencia histórica es un elemento o trama de la subjetividad política en donde hay un reconocimiento de los marcos históricos, sociales, culturales que entrecruzan las biografías. Las narraciones que son contadas a los niños y niñas se quedan ancladas a sus esquemas informacionales con los que representan la realidad, entienden y organizan el mundo con lo que se va configurando su conciencia histórica.

La subjetividad política es una relación con la realidad, por lo tanto, para ser sujeto político se requiere tener conciencia histórica. Esto es ilustrado con la expresión de uno de los participantes: "El obrero no es un sujeto político porque él sólo trabaja, entonces nunca tiene tiempo para escuchar las noticias y saber qué es lo que pasa". Este "trozo narrativo' deja entrever que los medios de comunicación son un importante agente que les narra y les aporta información y, por lo tanto, los guía en sus posicionamientos y pensamientos con respecto a ciertos temas relacionados con la política.

Las actividades narrativas realizadas permitieron que los niños y niñas, además de expresar la información que cada uno tenía, debatieran y contrastaran sus opiniones, reafirmaran o negaran sus relatos y los de otros. Además, les permitió comprender que lo narrado tiene efectos sobre ellos; por lo tanto, lo narrado tiene un carácter histórico y contextualizado en sus vidas, como cuando 
expresan los efectos que tendrían los resultados del plebiscito por la paz, realizado en el país en octubre del 2016. Narrar, ser 'empalabradores' de las realidades que acontecen, les revelaba que pertenecen a la historia y que se mueven en un espacio público instituido el cual no pueden evadir. Cuando esa realidad nombrada y revelada con palabras tenga una afectación propia en los niños y niñas, sus palabras deberán tomar forma de acción para enfrentar esas situaciones. De tal modo que, lo político, como afirma Arendt (citada en Govea, 2010, p.220), “es abordado por su carácter fenoménico, como revelación de sí en el espacio de aparición". Así, mediante la imaginación narrativa planteaban acciones que efectuarían frente a su realidad dada; por ello, hacer legible la realidad mediante su enunciación demanda que haya un agente de acción frente a ella.

\section{Subjetividad política como un acto de proyección y de 'promesa': el sujeto político como un sujeto de posibilidad}

Para transformar una realidad que se quiere cambiar se debe reconocer -la conciencia histórica- y luego, imaginarla diferente. Narrar no es solo contar aquello que ya aconteció y que podemos recordar, también es la oportunidad de relatar aquello que queremos que ocurra, aquello que proyectamos mediante la imaginación narrativa. En la investigación emergieron narrativas en las que los niños y niñas soñaron un destino deseado y una existencia en otras condiciones. Imaginar narrativamente plantea otros devenires en donde se da cuenta de una preocupación por el bienestar propio y de otras personas, narrando sueños que expresan la responsabilidad, conciencia y preocupación por 'otros'; así quedó plasmado en los si- guientes 'trozos narrativos': "Yo tengo muchos deseos: es estar en paz con mi familia y amigos", "Yo quiero un mundo tranquilo en el que se haga la paz, donde no roben, no maten y secuestren y haya una buena convivencia entre las demás personas", "Mi sueño es ser doctora, curar la gente, salvar los animales, quiero ser genial, quiero ser una salvadora". Así, expresan que no sueñan solo para ellos y ellas, sueñan para 'otros' un futuro de bienestar colectivo y valoran lo común.

Narrar y proyectar otras maneras de existencia podría jalonar procesos personales y sociales para hacer realizables esos sueños. Por eso expresaban: “Quiero esforzarme mucho para lograr mi sueño" y "nunca abandonen sus sueños, síganlos hasta cogerlos". Lo importante de la proyección es que, en esta ópera, a manera de 'promesa', como lo diría Ricoeur (citado en Ruíz y Prada, 2012, p.84), "el sujeto se compromete con su palabra y dice que hará mañana lo que dice hoy". La 'promesa' nos moviliza a actuar, a intentar realizarla, a buscar su cumplimiento, a no quedarnos prisioneros del pasado y a otorgar nuevos sentidos al futuro propio y compartido. Así, la proyección le otorga a la subjetividad política los sentidos para construir el porvenir al permitir que se reconozcan como 'personajes' capaces de ciertas realizaciones, como agentes de acciones futuras.

Muchas de sus narrativas son un proyecto ético con un alto contenido político, pues sus proyecciones implican un 'cuidado de sí' y 'cuidado del otro', un reconocimiento de nos-otros, por ejemplo: "Yo quiero de mi comunidad que los niños no fueran ladrones, ni que se metieran en vicios y yo les doy un consejo a los niños, que no se metan 
en vicios, ni que se vuelvan ladrones, o cualquier cosa, etcétera". Fueron construyendo narrativamente una conciencia ético-moral, una preocupación por el otro, como cuando expresaban: "Yo quiero mucho y sueño con la paz, no a la violencia, no peleen con los demás, ámense los unos a los otros", "Yo quiero que todos nos queramos entre nosotros mismos, nos valoremos, nos amemos para tener un mundo mejor para mejorar nuestra humanidad". Sus narrativas son 'heterónomas' en el sentido de Emmanuel Levinas (citado por Bárcena y Mélich, 2000), entendiendo la 'heteronomía' "como principio de obligaciones y responsabilidades morales para con el otro" (p.130). Siguiendo al autor, una subjetivación ética nace como respuesta, como responsabilidad al otro; esta responsabilidad es un momento constitutivo y fundante de la subjetividad y supone la irrupción de la alteridad.

\section{Subjetividad política como autonomía}

En las narrativas de los niños y niñas se exteriorizaron sus formas de pensar frente a ciertas realidades socio-culturales del contexto, pensamientos que se gestan en las relaciones interpersonales que establecen con lo otro y los otros, siendo el mismo sujeto quien determina qué aspectos toma para sí y nutre sus concepciones. De acuerdo con Rodríguez y Artazcoz, "la autonomía se alcanza a través de un procedimiento de educación social" (2004, p.166), en el cual el sujeto entra en relación dialógica con los demás y se forman conjuntamente, construyendo cada uno sus opiniones y posturas personales.

De acuerdo con los relatos de la mayoría de los niños y niñas, sus pensamientos están ligados a los medios de comunicación; sus formas de pensar se configuran conforme a lo que ven en la televisión, lo que escuchan en la radio y lo que leen en internet. Tal es el caso que cuando se les preguntaba dónde hay un político, los niños decían "en la televisión", "la radio", "el equipo", "en el computador" y cuando evocaban el proceso de paz que se estaba llevando a cabo en el país con las FARC-EP afirmaban: "En internet yo vi dice que la guerrilla no van no va a llegar al acuerdo, son mentirosos y tramposos"; "Los guerrilleros no cumplen, entregan las armas y siguen secuestrando a la gente, lo escuché en internet, ellos no quieren cambiar"; "En internet muestran que uno dice es el fin de la guerra, y el otro dice que el acuerdo no garantiza la paz, entre ellos se contradicen".

Desde esta perspectiva, y con base en la educación social que permite alcanzar la autonomía en el sujeto, se puede afirmar que los niños y niñas están en un proceso de construcción de sus pensamientos, siendo principalmente los medios de comunicación quienes brindan dicha educación para la construcción de su autonomía. Es decir, son una influencia -no determinista- externa que por medio del lenguaje proporciona una visión de la realidad posibilitándole a los niños y niñas construir sus opiniones y formas de pensar frente a esta.

Al comprender que la autonomía se construye en las relaciones comunicativas con los otros, las narrativas se convierten en una posibilidad para construirla o deconstruirla. Por tanto, en el trabajo de campo realizado, fueron una posibilidad para confrontar a los niños y niñas frente a las posturas que ya habían construido, para que estos las reafirmaran, las analizaran, las transfor- 
maran o las retroalimentaran a través de la interpelación narrativa, es decir, fueron experiencias dialógicas donde había una pregunta por su pensamiento, por su postura, el porqué de ello y no otras maneras de visualizar y analizar situaciones. De esta manera, se contribuyó a la construcción de argumentos propios como un modo para acercarlos a una autonomía de pensamiento.

Un ejemplo de esta interpelación narrativa fue cuando una niña expresó: "El presidente es muy malo, le voy a decir a mi papá, que es policía, que mate al presidente". Ante este enunciado, en el grupo surgieron interrogaciones como ¿matar al presidente es bueno?, ¿la niña no es tan mala como el presidente por querer matarlo?, ¿querer matar a un malo no es también malo? Ante esta interpelación, la niña, mediante la verbalización de su pensamiento, debió distinguir la doble valencia de su moralidad para descifrar su posición.

Como en el ejemplo anterior, los niños y niñas narraron muchos otros pensamientos en los cuales develaban sus posturas y su formación ético-moral. Lo importante de poner en palabras todas estas concepciones que tienen de las realidades socio-cultuales es que hay un proceso de reconocimiento de lo que son y cómo piensan. Mediante las narrativas, estas posturas entran en diálogo con otras, lo cual permite que el sujeto reafirme su pensamiento tomando mayor firmeza o, por el contrario, se mueva a nuevas perspectivas.

\section{Subjetividad política como relaciones de poder y acción con los otros.}

La relación con 'otros' se hizo latente en los discursos de los niños y niñas: "El señor de la piscina era nuestro amigo, a él lo mataron y a nosotros nos tocó venir para acá"; "Dibujé una casa en el árbol en la que juego con mis amigos y mis primos"; "Me encanta estar con mi familia y mi amiga que vivimos juntos jugando en los árboles". Entre muchos otros relatos, los niños y las niñas expresaron las experiencias humanas en relación con sus padres, abuelos, hermanos, amigos, primos, compañeros de escuela, vecinos, maestros, y un sinnúmero más de actores que han incidido en su subjetivación. Estas personas se convierten en esos otros significativos con quienes se comparten historias, con quienes se sueña, con quienes se transita la vida y con quienes se intercambian experiencias por medio del lenguaje. En consecuencia, se configuran modos de pensar y de actuar, pues los seres humanos somos seres de afectación, en una relación dialógica y recíproca donde conjuntamente, a través de experiencias cotidianas, nos formamos y dejamos trazos de sí mismos en la vida del otro (Ocampo, 2011).

Este reconocimiento que hacen los niños y niñas de esos otros significativos por medio de las narrativas es fundamental porque se develan como personajes con quienes actúan en su diario vivir en favor de sí mismos, de otros, del entorno, de las realidades. Además, este reconocimiento desemboca en una conciencia ético-moral que se traduce en una pregunta por el otro y, más allá, en una responsabilidad social con este, que implica visibilización, acogida y reconocimiento; acciones de un sujeto político.

Para la configuración de la subjetividad política es fundamental -además del encuentro, la interacción y el reconocimiento del otro en la vida propia- el accionar colectivo, el hacer, pensar y actuar en conjunto 
con el otro. En las primeras narraciones de los niños no había experiencias ni alternativas que ellos establecieran para solucionar problemas sociales, que relataran episodios de colectividad en pro de comprender la realidad, transformarla e instituir otra sociedad con los demás. Al iniciar, sus procesos se caracterizaban por dos aspectos: El primero de ellos, en concordancia con el planteamiento de 'personajes beneficiarios', es que los niños y niñas no se sitúan como corresponsables de su desarrollo, con capacidades de agenciar otras posibilidades de vida y consideran que son los otros los que deben suplir sus necesidades. El segundo aspecto radica en que las relaciones interpersonales que se dan en el ámbito familiar y escolar de acuerdo con las narraciones de los niños y niñas- son violentas, lo cual dificulta la acción con el otro, pues esta debe iniciar desde el respeto, la tolerancia y el diálogo con el otro para poder actuar en conjunto. Estas relaciones violentas se pueden apreciar en los siguientes relatos: "Un día una niña me empujó y yo le respondí, sólo porque la chaqueta me detuvo porque si no, a esa niña le va mal"; "Un día estábamos jugando, entonces, él me pegó, yo le pegué, él me pegó, yo le pegué, él me pegó, yo le pegué".

Estas y otras narraciones posibilitaron comprender que las relaciones de poder en este grupo se determinaban sobre el otro, quien tuviera más fuerza "ganaba". Estas dinámicas sociales dificultan la acción con los otros porque no hay una relación dialéctica para solucionar problemas, no existe un poder que potencie relaciones horizontales para responder a estos y construir otro ambiente escolar caracterizado por el respeto y valoración del otro.
Partiendo de esta realidad, las narrativas fueron una posibilidad para empezar a estructurar otras dinámicas de relaciones entre los niños y niñas en el ámbito escolar y que empezaran a movilizarse hacia la acción con otros; no de experiencias de vida, sino de discursos y cuestionamientos que emergieron por parte de los docentes: "¿Tu compañero te quiso lastimar con intención? ¿Analizaste el contexto de cómo ocurrió todo?" Lo que se propone con estos interrogantes es narrar y dialogar sobre lo que acontece en las relaciones humanas e imaginar narrativamente las intenciones del otro como un medio para resolver conflictos de manera consensuada y acertada, configurando sujetos con capacidad de leer situaciones y actuar políticamente. Desde esta perspectiva, las narrativas se convierten en un medio para resolver conflictos a partir de los relatos, la escucha y la comprensión de las acciones del otro, constituyendo así, sujetos de palabras, sujetos políticos.

Estos cuestionamientos frente a las acciones violentas de los estudiantes eran un catalizador positivo para mejorar las relaciones escolares. Antes de responder con mano propia, muchos niños y niñas evaluaban la situación y preferían "poner la queja" a los maestros para que, desde una acción con ellos, se plantearan soluciones desde relaciones horizontales mediadas por el diálogo, forjando con ello una coherencia entre el decir y el actuar. Así mismo, en sus narraciones finales aparecían relatos en los que se reconocía al otro como un ser importante para accionar juntos, como sujetos con potenciales políticos, y existía una acogida que posibilitaba pensarse en acción con. "Yo lo dejo entrar porque ayuda a las personas"; 
"Si lo dejo entrar, porque él dijo que ya no pega [ya no golpea a las personas]"; "Sí la acepto porque es muy cariñosa".

\section{Subjetividad política como ampliación del círculo ético.}

El reconocimiento que las narrativas posibilitan a los niños y niñas no es solo de sí mismos y de sus experiencias, sino también de los otros y de sus realidades de vida. Las narrativas permitieron conocer historias que ampliaron y flexibilizaron el círculo ético de los niños y niñas, al escuchar y comprender los relatos de vida que dejaban entrever su realidad y las vivencias significativas que han gestado en sus relaciones con otros. Esto posibilitó una visibilización de sus sentimientos, miedos, sueños y experiencias, tal y como lo ilustran estos relatos: "He sentido miedo de que nos fuéramos a quedar en la calle porque mi mamá no podía trabajar así embarazada y estaba sola y nosotros no teníamos comida [...]"; "Yo he sentido miedo a que me maten cuando mi mamá y mi padrastro pelean”. Esas prácticas del lenguaje posibilitaron un reconocimiento mutuo de los niños y niñas como seres humanos y una comprensión de sí mismos, de los otros, del mundo que los rodea (Delory, 2015).

Así mismo, como investigadores, facilitamos espacios para escuchar otras narrativas, a través de unos videos de la UNICEF en los que se plasmaban realidades de vulnerabilidad de otros niños y niñas del mundo, para que a través de la imaginación narrativa lograran ponerse en el lugar de ellos, se despertaran emociones políticas como la empatía, y se establecieran alternativas, inicialmente desde el lenguaje, para cambiar o mejorar sus historias de vida, su presente y su futuro, como una responsabilidad que se adquiere al estar en la sociedad.

Este acercamiento a otras realidades es importante en la formación política de los niños y niñas porque posibilita que se sensibilicen y vayan adquiriendo una responsabilidad con el pasado, el presente y el futuro de la sociedad como sujetos políticos. Esta sensibilización se vio materializada en el trabajo de campo. En un primer momento, cuando se proyectaron los videos, los maestros observamos un silencio profundo; interés; caras de sorpresa, indignación y repudio; sonrisas; expresiones como "quiero llorar", entre muchas otras, que nos posibilitaron hacer lectura de las emociones que suscitaban aquellas imágenes. En un segundo momento, verbalizaron sus sentimientos: "Sentí mucha tristeza al ver como ellos comían hierba porque no tenían comida. Nosotros podemos ayudarlos, si sobra comida en mi casa yo se las doy".

En sus expresiones verbales y no verbales hay un proceso significativo referente a la configuración de la subjetividad política mediante la narración, pues los niños y niñas ampliaron su círculo ético visibilizando situaciones quizá ajenas a su propia realidad, pero que generaron conmoción y valoración por lo que son, tienen y donde viven: "Y así nosotros alegando porque no nos gusta una sopa". Lo importante de haber visibilizado esas realidades es que los niños y niñas se pusieron en el lugar del otro a través de la imaginación narrativa y establecieron alternativas para solucionar problemas. Esto es fundamental cuando se pretende configurar nuevas maneras de ver el mundo, leerlo y actuar en él con una responsabilidad consigo mismo y con los otros. "Quizá hay que 
insistir en que el ejercicio de la subjetividad política pasa por la formación de nuestra capacidad de conmovernos ante el dolor de los otros y de buscar las maneras de actuar a favor del nunca más" (Ruiz y Prada, 2012, p.71).

\section{Conclusiones: las narrativas como un espacio para subjetivar lo político}

El trabajo narrativo llevado a cabo durante esta investigación permitió que los niños y niñas ampliaran, dilucidaran y debatieran imaginarios, imágenes o representaciones de lo que es la política y lo político. Se develaron potencias para que ellos y ellas se reconocieran como sujetos políticos, con capacidad de agencia.

A través de las narrativas surgieron «actos de reconocimiento» como agentes políticos, una construcción de 'sí mismo como otro' de los niños y niñas. Las narrativas potencian algunos elementos o tramas de la subjetividad política y de eso deriva que el niño y la niña se reconozcan a sí mismos como otros, como sujetos políticos. Con las narrativas se da sentido a sus acciones cuando son en pro del otro; narrar permite la comprensión de los significados políticos que tienen esas acciones en tanto el sujeto narrador/protagonista del relato se convierte en el 'otro' de su propia historia, es decir, permite construir la dimensión de alteridad de sí mismo.

El reconocimiento de sí-mismo-comootro es un reconocimiento del 'yo' bajo la condición de 'otro'. Narrar fue tomar conciencia de sus vidas - políticas-, lo cual surgió ante la pregunta sobre lo que han hecho con carácter político. Así, todas las narrativas tienen una misma propiedad: ser acciones para/por/frente a un 'otro', «Yo alteridad».

En esta investigación, los niños y niñas fueron 'personajes' de sus propias narrativas, que fueron sus vidas mismas. Los niños y niñas construyeron tramas alrededor de sus vidas. En las historias narradas, sus autobiografías y sus memorias, re-construyeron las «tramas» de su subjetividad política. Aquí, el término «tramas» tiene dos sentidos: por un lado, desde los postulados de Alvarado, Ospina, Botero y Muñoz (2008), las tramas son aquellos elementos que integran la subjetividad política o la manera como esta se despliega; por otro lado, desde la narratología, con los planteamientos de Ricoeur (2006), las tramas son las estructuras, el proceso integrador o la composición que dota de identidad a la historia narrada, en esta síntesis se integran diversos acontecimientos o múltiples sucesos para ser transformados en una historia.

Así pues, desde las historias, anécdotas y experiencias de vida contadas por los niños y niñas, decimos que lo narrado ayuda a configurar la subjetividad política porque los trozos y las tramas que aparecen en los relatos (la identidad, la memoria, el posicionamiento, la proyección, la autonomía de pensamiento, la ampliación del círculo ético, la conciencia histórica, la acción con el otro, la negociación del poder) se van entramando o 'sintetizando' como narración y como subjetividad política en el reconocimiento que los niños y niñas hacen de esos elementos. En pocas palabras, las tramas de la subjetividad política se van entramando en las tramas de la narración. 
Estas tramas sólo pueden ser integradas o sintetizadas en una historia narrada y en la subjetividad si son reconocidas por los autores/narradores de las historias. El reconocimiento es lo que hace de la subjetividad política una subjetividad narrada y entramada; y este reconocimiento se da porque la subjetividad política se hace inteligible, a través de lo narrado, en acciones vividas concretas. Narrar historias de vida proporciona imágenes concretas al concepto «político» por medio de las acciones y los personajes del relato; las autobiografías son la forma narrativa de pensar lo político. Las acciones pasadas se narran para hacerlas comprensibles. Los sentidos políticos que contribuyen a subjetivar se construyen recordando su historia, su vida - política-.

La subjetividad política es [re]configurada por la historia narrada ya que el niño y la niña se pueden reconocer como sujetos políticos, pueden reconocer lo que hay de político en él o ella - en cuanto a sujeto-, lo político se devela en la existencia propia, en las experiencias cotidianas; se 'descubre' que lo político tiene una historia en cada uno, o mejor, cada uno tiene una historia política que narrar. Como plantean Ruíz y Prada (2012):

Si algo puede llamarse subjetividad política, tendrá que ser concebi- da de manera narrativa, es decir, en la construcción de relatos sobre sí mismo - en tanto individuo y como miembro de colectivos humanos que eventualmente poseen intereses compartidos-y en el significado que el sujeto les otorga a las prácticas sociales y políticas. [...] La subjetividad política sería, en todo caso, un universo discursivo-narrativo. (pp.51-52)

Hay una transformación simbólica en la manera como los niños y niñas se reconocen, se enuncian y se nombran. Lo narrado desarrolla cierta conciencia que permite que se identifiquen de otras maneras y denominen a sí mismos como sujetos políticos porque, como sostiene Ospina, Carmona y Alvarado (2014), la subjetividad política parte del reconocimiento de la potencia y la agencia, de crear nuevas maneras de nombrar, de identificar en el lenguaje posibilidades generadoras de nuevas realidades.

Es necesario dar sentidos políticos a las experiencias subjetivas porque, como plantea Ruíz y Prada (2012): "La subjetividad política se refiere a que somos sujetos políticos cuando nos percibimos a nosotros mismos, reflexivamente, como agentes sociales con conciencia de nuestra identidad histórica $[\ldots]$ y nos sentimos responsables de la dimensión política de nuestras acciones" (p.35).

\section{Notas}

1. Este artículo presenta los resultados del proyecto de investigación «Yo alteridad», el reconocimiento de 15 niños de la I. E. Antonio Derka, de Medellín, como «personajes» políticos a través de las narrativas. Este proyecto es presentado por los autores para optar al título de Licenciados en Pedagogía Infantil, en el marco de un programa de formación ciudadana de la Facultad de Educación de la Universidad de Antioquia y la Corporación Héctor Abad Gómez. El estudio se realizó entre febrero del 2016 y junio de 2017.

2. Para utilizar términos propios de lo narrativo, llamamos 'personaje' a esas 'maneras-de-ser' y lo utilizamos porque, los sujetos que se narran son 'personajes': el sujeto narrado. 


\section{REFERENCIAS}

Alvarado, S. V. (2009). La formación de la subjetividad y la identidad ético-política en la primera infancia. Memorias Foro Mundial de Grupos de Trabajo por la Primera Infancia: Sociedad Civil - Estado. Tomo 1. Manizales, Colombia: CINDE.

Alvarado, S. V., Ospina, H. F., Botero, P., y Muñoz, G. (2008). Las tramas de la subjetividad política y los desafíos a la formación ciudadana en jóvenes. Revista Argentina de Sociología, 6(11), 19-4. Disponible en: https://www.redalyc.org/articulo.oa?id=269/26911765003

Bárcena, F. y Mèlich, J. (2000). Paul Ricoeur: Educación y narración. En La educación como acontecimiento ético: natalidad, narración y hospitalidad (pp.91-124). Barcelona, España: Paidós Ibérica.

Delory, C. (2015). El relato de sí como hecho antropológico. En G. Murillo (comp.), Narrativas de experiencias en educación y pedagogía de la memoria (pp. 57-68). Buenos Aires, Argentina: Editorial de la Facultad de Filosofía y Letras Universidad. Disponible en: https://www.jstor.org/ stable/pdf/j.ctvtxw30v.5.pdf

Galeano, M. E. (2004). Diseño de proyectos en la investigación cualitativa. Medellín, Colombia: Fondo Editorial Universidad EAFIT.

Govea, J. (2010). Visión de la política en Hannah Arendt. Frónesis, 17(2), 217-240. Disponible en: https://dialnet.unirioja.es/ejemplar/497807

Kohan, W. (2007). Presentación y Política, educación y filosofía: la fuerza de la extranjeridad. En W. Kohan, Infancia, política y pensamiento (pp. 7-29). Buenos Aires, Argentina: Del estante.

Mèlich, J. (1994). Del extraño al cómplice: la educación en la vida cotidiana. Barcelona, España: Anthropos Editorial.

Ocampo, R. (2011). Estudios éticos políticos. Pluralismo, violencia y educación para la paz. Cali, Colombia: Universidad Autónoma de Oriente.

Ospina, M.C.; Carmona, J., y Alvarado S.V. (2014). Niños en contexto de conflicto armado: narrativas generativas de paz. Revista Infancias Imágenes, 13 (1), 51-59. DOI: https://doi. org/10.14483/16579089.7838

Piedrahíta, F. (2015). Introducción a la línea: investigación narrativa: estudio de la experiencia y la transformación. En Encuentro con-sentido pedagógico. Investigación Educativa: un horizonte político de ciudad (pp.74-81). Medellín, Colombia: Secretaría de Educación, Alcaldía de Medellín.

Ricoeur, P. (1996). Sí mismo como otro. Ciudad de México, México: siglo XXI.

Ricoeur, P. (2006). La vida: un relato en busca de narrador. ÁGORA. Papeles de filosofí, 25(2), 9-22.

Rodríguez, E. y Artazcoz, M. (2004). Política, autónoma y democratización en el pensamiento de Jean Piaget. Revista del programa de Estudios Políticos Universidad del Valle, (2), 161-186.

Ruíz, A., y Prada, M. (2012). La formación de la subjetividad política. Propuestas y recurso para el aula. Buenos Aires, Argentina: Paidós. 
Vargas, C. (2007). Formas del sujeto político en el panorama de lo contingente. Tabula Rasa, (7), 211-228. Disponible en: https://www.redalyc.org/articulo.oa?id=396/39600710 